\title{
The conceptual model of neuro-fuzzy regulation of the microclimate in the room
}

\author{
Andrey Karpenko, ${ }^{1, *}$ and Irina Petrova ${ }^{2}$ \\ ${ }^{1}$ Astrakhan State University, 414056 Astrakhan, Russia \\ ${ }^{2}$ Astrakhan State University of Architecture and Civil Engineering, 414056 Astrakhan, Russia
}

\begin{abstract}
The purpose of this study is to develop a model of neuro-fuzzy regulation of the microclimate in the room. The proposed model consists of an artificial neural network serving to form a comfort index PMV, a fuzzy logic controller for regulating temperature and humidity in the room. This approach makes it easy to manage these parameters through an estimate of the PMV index, which indicates the level of thermal comfort in the room.
\end{abstract}

\section{Introduction}

Thermal comfort in the room has a direct impact on human performance and indirect influence on energy efficiency. Temperature control is one of the strategies for achieving individual comfort in the room, although temperature is only one of the factors that affect the level of thermal comfort. Standard GOST R ISO 7730 (2011) defines thermal comfort as "a state that expresses satisfaction with the thermal environment".

The index, called the predicted mean vote (PMV), was proposed by Fanger [1] to determine the average voice of a large group of people in the scale of thermal sensation. This index depends on six factors: metabolic rate, clothing insulation, air temperature, humidity, air move speed and average radiant temperature. PMV is a subjective quantification of a comfortable feeling in the premises.

A lot of scientific articles are devoted to ways of applying machine learning methods for predicting parameters that affect thermal comfort.

In Huang work [2], the artificial neural network (ANN) model was used to predict the temperature in the building. The model well fixed the internal dynamics of the system under study. In the modeling, the model gave low inaccuracies indices for the forecast for the next few days.

The Argiriou study [3] describes the development of an ANN controller consisting of a meteorological module that predicts the temperature of the environment and solar radiation, a module for determining the temperature inside the room.

Ferreira paper [4] addresses the problem of controlling the heating and air conditioning (HVAC) system in order to achieve the desired level of thermal comfort and energy saving. Thermal comfort, estimated using the PMV index, is achieved with minimal power consumption. It is estimated that the energy savings resulting from the application of the method exceed $50 \%$.

\footnotetext{
*Corresponding author: andreykotor@gmail.com
} 
In addition, it is possible to single out works investigating the application of fuzzy logic controllers (FLC) of internal thermal parameters, see Calvino [5] and Dounis [6]. For example, in Berk study [7], the synthesis of the PID controller of fuzzy logic and the classical PID temperature controller was used to control the microclimate. For more information on fuzzy logic, see the works of Professor Zadeh [8], the author of this term and one of the founders of the theory of fuzzy sets.

Tarun paper [9], was proposed design of a room temperature and humidity controller based on fuzzy logic. The model consists of two controllers with fuzzy logic for controlling temperature and humidity, respectively. The first controller takes two input values - the current temperature determined by the temperature sensor and its deviation from the userset temperature, and accordingly controls the speed of the heat and cooling fans. When the current room temperature reaches the set point, it serves as one of the input signals for the second fuzzy controller, which controls the humidity. The system has an ideal level of relative humidity for a user-defined temperature. The current humidity detected by the sensor in the room serves as the second input of the controller. The humidifier and the speed of the exhaust fan are con-trolled accordingly to maintain a suitable humidity level for this temperature.

Fuzzy sets find a place in optimization problems. Al-Gunaid et all [10] apply the fuzzy set theory to improve the quality of decision making in the power system using renewable energy sources (RES)

In the framework of this study, a model is proposed for assessing thermal comfort using both ANN and fuzzy logic. In contrast to Tarun work in the model being created, the PMV index, which comes from the ANN, will be used as input parameter in addition to air temperature and humidity level in the room. See Karpenko [11] on the advantages and disadvantages of the neuro-fuzzy model of indoor climate control are described.

The neural network was trained on the values of air temperature and relative humidity and is designed to calculate the PMV index

The use of this parameter is convenient for creating fuzzy logic rules since the standard describes a comfort scale, which will allow more accurate regulation of temperature and humidity values, since these parameters directly affect the PMV index and are linked together.

The simulation was carried out in Matlab software.

\section{Structure of the proposed model}

To train the neural network, which generates the comfort index PMV, the parameters of the air temperature in the room and relative humidity of air were used. At this stage, ANN does not have the ability to predict the expected comfort index. The controller did not take into account physiological parameters, air speed and individual user characteristics (for example, age and clothing). The inclusion of these parameters and the possibility of a temperature forecast, in the future, will provide an opportunity to more realistically describe the thermal comfort in the room. In fact, in its current state, the fuzzy controller is operated only by the internal temperature, the relative humidity and the PMV comfort index generated by the neural network module.

The proposed model has a structure, consisting of a neural-fuzzy controller, a HVAC system control device and a room. The measured parameters of temperature and relative humidity in the room get to the input of the neuro-fuzzy controller, which in turn forms a control signal for the climate control device (air conditioner) in the room.

Figure 1 shows a fragment of a neural-fuzzy controller. The controller obtains clear numerical values of temperature $(\mathrm{T})$ and relative humidity $(\mathrm{RH})$, which are used to calculate the PMV comfort index with the help of ANN. These data are converted to 
linguistic values using the selected set of membership functions. Fuzzy logic controller (FLC), based on a set of rules, adjusts respectively either the value of the temperature, or the relative humidity or both. After this, the FLC transfers control to the HVAC device, where, based on the new control signals, the actual values of temperature and humidity in the room are corrected.

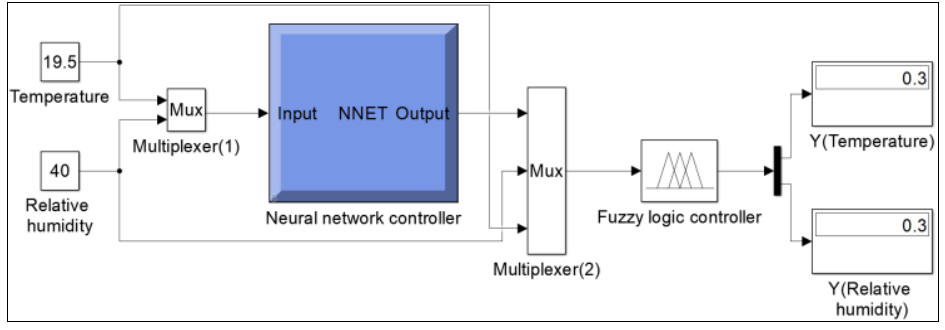

Fig. 1. Fragment of the neural-fuzzy controller.

\section{Neural network settings}

Figure 2 shows the structure of the neural network used. This two-layer network with direct signal transmission has a hidden layer with 40 neurons and a linear output layer with one neuron. The hidden layer has a sigmoidal activation function. They were trained using the quasi-Newton method.

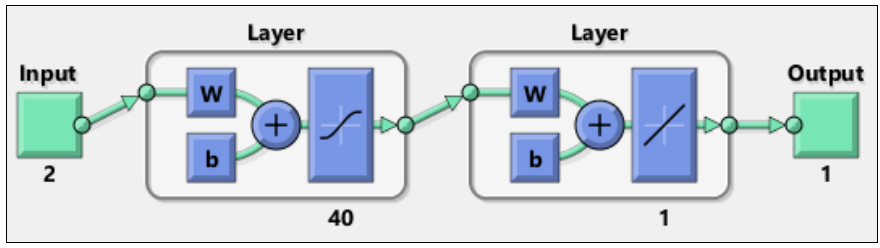

Fig. 2. Structure of neural network.

The input parameters of the ANN are the room temperature (T), relative humidity $(\mathrm{RH})$. The training set of temperature was given in the range of 10 to 39 degrees in steps of one degree; the training set of relative humidity was given in the range of 40 to 80 percent in increments of 5 percent. Other parameters (clothes) were specified as constants. The ANN model calculates the PMV comfort index in accordance with the requirements described in the standard GOST R ISO 7730 [12].

According to the normative document "Hygienic requirements for microclimate of industrial premises" [13] values of optimal temperatures in the room in the warm season are $23-25^{\circ} \mathrm{C}$, and in the cold $22-24^{\circ} \mathrm{C}$. The optimum moisture values lie in the range from 40 to 60 percent. Table 1 shows the results of modeling the ANN on the optimal values of the parameters.

Table 1. The results of the ANN simulation.

\begin{tabular}{|c|c|c|c|c|c|c|}
\hline Temperature, ${ }^{\circ} \mathbf{C}$ & 22 & 22 & 23 & 23 & 24 & 25 \\
\hline $\begin{array}{c}\text { Relative } \\
\text { humidity, \% }\end{array}$ & 45 & 60 & 45 & 50 & 55 & 60 \\
\hline PMV, point & -0.94 & -0.78 & -0.58 & -0.54 & -0.18 & 0.16 \\
\hline $\begin{array}{c}\text { Relative error, } \\
\text { \% }\end{array}$ & 5.99 & 2.75 & 7.09 & 5.72 & 0.41 & 15.09 \\
\hline
\end{tabular}


The results obtained are close to the values of the comfort zone (from -1 to 1), so we can conclude that the ANN works correctly.

\section{Designing the fuzzy logic controller}

Fuzzy controllers allow you to apply linguistic rules instead of complex analytical expressions. To build a rule base, need to define input and output linguistic variables. In this work, FLC has three input variables: "temperature", "relative humidity" and "PMV index". As output linguistic variables, two "regulation factors" are used, which can be represented as regulating the operating mode of the HVAC control device. Both variables have similar membership functions, and correspond respectively to air temperature and relative humidity. Table 2 describes the linguistic values used.

Table 2. Linguistic variables.

\begin{tabular}{|c|c|c|c|c|c|c|c|}
\hline $\begin{array}{c}\text { Symbolic } \\
\text { designation }\end{array}$ & NB & NM & NS & Z & PS & PM & PB \\
\hline Notation & $\begin{array}{c}\text { Negative } \\
\text { Big }\end{array}$ & $\begin{array}{c}\text { Negative } \\
\text { Middle }\end{array}$ & $\begin{array}{c}\text { Negative } \\
\text { Small }\end{array}$ & Zero & $\begin{array}{c}\text { Positive } \\
\text { Small }\end{array}$ & $\begin{array}{c}\text { Positive } \\
\text { Middle }\end{array}$ & $\begin{array}{c}\text { Positive } \\
\text { Big }\end{array}$ \\
\hline
\end{tabular}

\subsection{Structure of the term set "Temperature"}

The proposed model operates at a temperature in the range of $0{ }^{\circ} \mathrm{C}-45^{\circ} \mathrm{C}$. The membership functions are described in Table 3.

Table 3. Membership functions for temperature.

\begin{tabular}{|c|c|c|c|c|c|}
\hline $\begin{array}{c}\text { Membership } \\
\text { functions }\end{array}$ & NB & NS & $\mathrm{Z}$ & PS & PB \\
\hline Range $\left({ }^{\circ} \mathbf{C}\right)$ & $0-19$ & $17-23.5$ & $22-25$ & $23.5-30$ & $28-40$ \\
\hline
\end{tabular}

The function negative big (NB) at to $0^{\circ} \mathrm{C}$ is not usual for a room; this value was taken to simulate extremely cold conditions. Similarly, to simulate extremely warm conditions, values were set for the function positive big (PB). Figure 3 shows a graph of membership functions for the term set "Temperature".

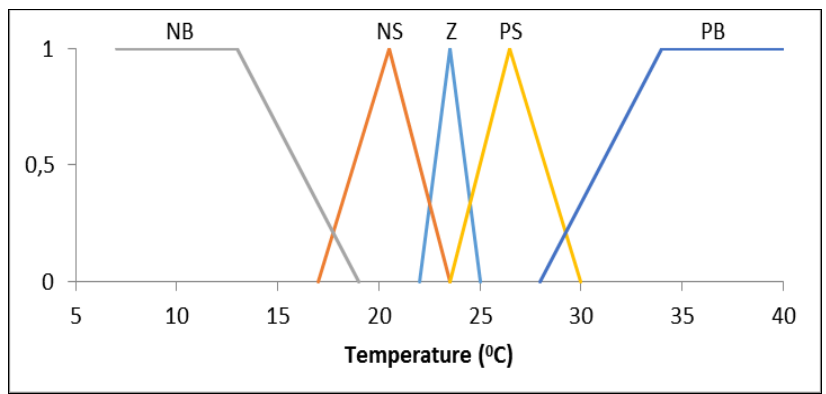

Fig. 3. Plot of membership functions for temperature.

\subsection{Structure of the term set "Relative humidity"}

The recommended level of relative humidity corresponds to a value of 45-55 percent. The membership functions are shown in Table 4. 
Table 4. Membership functions for relative humidity.

\begin{tabular}{|c|c|c|c|}
\hline $\begin{array}{c}\text { Membership } \\
\text { functions }\end{array}$ & NS & Z & PS \\
\hline Range (\%) & $20-50$ & $45-55$ & $50-80$ \\
\hline
\end{tabular}

Figure 4 shows a graph of membership functions for the term set "Relative humidity".

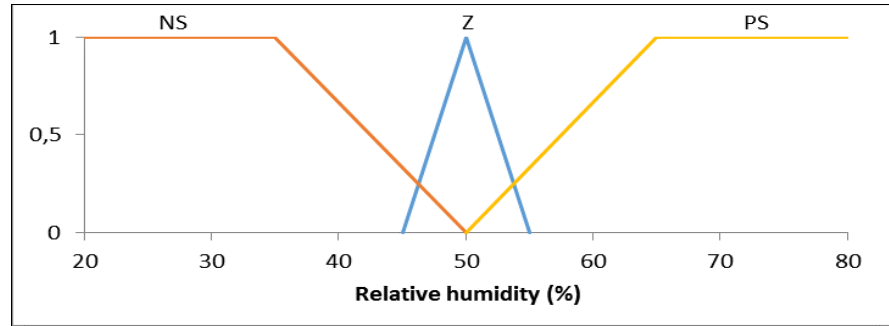

Fig. 4. Plot of membership functions for relative humidity.

\subsection{Structure of the term set "PMV index"}

The PMV comfort index is graded on a scale from -3 to 3 , with values in the range from -1 to 1 being considered the most comfortable. Values from -0.5 to 0.5 correspond to thermal comfort. To consider this, the appropriate form was chosen for the membership function (Z). At the same time, the value of the PMV comfort index when calculating it can go beyond the boundaries from -3 to 3 . But in this case, the results are taken accordingly as extremely cold or extremely warm. Based on this scale, the membership functions were constructed (Table 5).

Table 5. Membership functions for PMV index.

\begin{tabular}{|c|c|c|c|c|c|c|c|}
\hline $\begin{array}{c}\text { Membership } \\
\text { functions }\end{array}$ & NB & NM & NS & Z & PS & PM & PB \\
\hline $\begin{array}{c}\text { Range } \\
\text { (points) }\end{array}$ & $\begin{array}{c}\text { from }-3.5 \\
\text { to }-2.5\end{array}$ & $\begin{array}{c}\text { from }-2.5 \\
\text { to }-1.5\end{array}$ & $\begin{array}{c}\text { from }-1.5 \\
\text { to }-0.5\end{array}$ & $\begin{array}{c}\text { from }-1 \\
\text { to } 1\end{array}$ & $\begin{array}{c}\text { from } 0.5 \\
\text { to } 1.5\end{array}$ & $\begin{array}{c}\text { from } 1.5 \\
\text { to } 2.5\end{array}$ & $\begin{array}{c}\text { from } 2.5 \\
\text { to } 3.5\end{array}$ \\
\hline
\end{tabular}

The graph of membership functions for the term set "PMV Index" is presented in Figure 5.

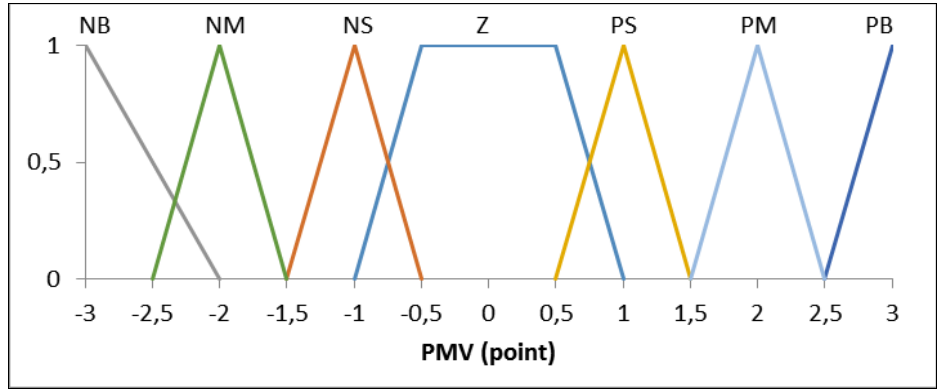

Fig. 5. Plot of membership functions for PMV index.

\subsection{Structure of the term set "Regulation factor"}

The HVAC control unit (air conditioner) can have temperature control functions (heating and cooling), humidity control (dehumidification and humidification of air) depending on 
the user's preferences. If the current room temperature is below the desired temperature, then this device automatically turns on, changing the operating mode depending on the temperature difference. The humidity level is controlled by the same rules, while the temperature fluctuations in the room are minimal.

There is a relationship between temperature and relative humidity. The growth or decrease in humidity affects the value of the comfort index so that when the humidity increases in a low temperature environment, the value of the PMV index increases. With a decrease in humidity in high-temperature environments, the value of the PMV index falls. Obviously, even if the temperature is within acceptable limits, the value of the PMV index can be adjusted using humidity control.

Thus, it is possible to formulate the membership functions for the control signal that regulating parameters of temperature and humidity. Values range from -1 to 1 (Table 6).

Table 6. Membership functions for regulation factor.

\begin{tabular}{|c|c|c|c|c|c|}
\hline $\begin{array}{c}\text { Membership } \\
\text { functions }\end{array}$ & NM & NS & Z & PS & PM \\
\hline $\begin{array}{c}\text { Range } \\
\text { (points) }\end{array}$ & $\begin{array}{c}\text { from }-1 \\
\text { to }-0.3\end{array}$ & $\begin{array}{c}\text { from }-0.6 \\
\text { to } 0\end{array}$ & $\begin{array}{c}\text { from }-0.3 \\
\text { to }-0.3\end{array}$ & $\begin{array}{c}\text { from } 0 \text { to } \\
0.6\end{array}$ & $\begin{array}{c}\text { from } 0.3 \\
\text { to } 1\end{array}$ \\
\hline
\end{tabular}

We accept a change of 4 degrees as corresponding to the membership functions "NS" and "PS" (for humidity control 10\%). For the "NM" and "PM" membership functions, we set the change to 8 degrees for temperature and $20 \%$ for humidity control. The membership function " $Z$ " corresponds to the most comfortable thermal conditions in the room. The graph of membership functions for the term set "Regulation factor" is shown in Figure 6.

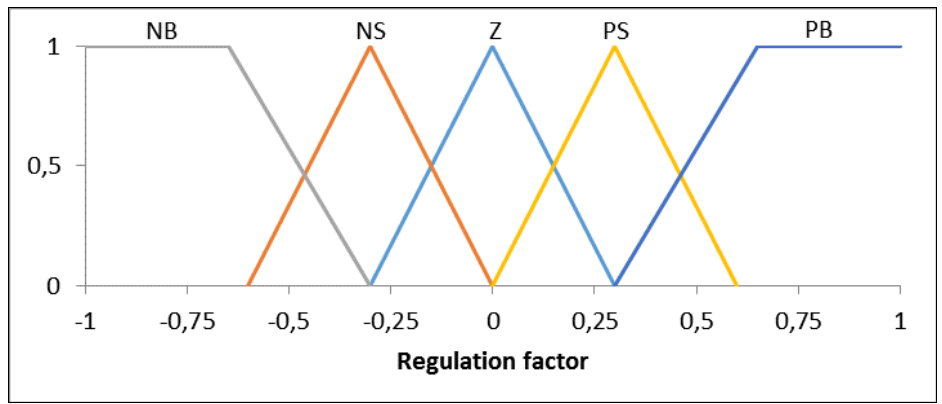

Fig. 6. Plot of membership functions for regulation factor.

\subsection{Rule base}

The fuzzy controller operates with linguistic variables, using the fuzzy inference mechanism based on the set of fuzzy "IF-THEN" rules. Thus, the output mechanism determines the correct result in accordance with these rules. The fuzzy controller's rules base, developed for the proposed model, consists of 35 rules. The rules were drawn up so that the PMV value was as close to the thermal comfort position. For this was used the method of complete enumeration of the membership functions of the regulation factor for combinations of input parameters of temperature and humidity. Among all the results obtained, a ratio was chosen at which the value of the PMV index was as close as possible to zero.

If the room temperature is $30^{\circ} \mathrm{C}$, the relative humidity is $79 \%$, then the comfort index value generated by the $\mathrm{ANN}$ is 1.91 points. This temperature refers to the range of $\mathrm{PB}$ values - a very high temperature. The humidity value falls within the PS range - high humidity. Now it was necessary to adjust these parameters so that the PMV index falls in 
the range of comfort values. For example, the rule for such parameters can be written as follows: "IF Temperature (PB) And Humidity (PS) And PMV (PM) THAT Temperature should be slightly lowered (NS) And Humidity - leave unchanged (Z)".

With regulation, the temperature drops by $4^{\circ} \mathrm{C}$. The new temperature value $\left(26^{\circ} \mathrm{C}\right)$ makes it possible to obtain a PMV value of 0.65 points. This is an acceptable result and suitable for providing thermal comfort, but it can be corrected by changing the relative humidity in the room. Thus, the changed rule looks like this: "IF Temperature (PB) And Humidity (PS) And PMV (PM) THAT Temperature - should be slightly lowered (NS) And Humidity is greatly lowered (NM)".

So, when adjusting, we get new temperature $\left(26^{\circ} \mathrm{C}\right)$ and humidity $(60 \%)$ values. The final value of the PMV index will be 0.48 points. This value is closer to the zero mark than the one obtained with the previous rule. Regulation relatively of the PMV index avoids the formation of complex interrelationships between the parameters that affect the microclimate, and focus on achieving the maximum level of thermal comfort.

\subsection{Model limitations}

The model described in this paper has several limitations. First, other important factors contributing to comfort (for example, light comfort, draft in the room and other variables associated with PMV calculation) are not taken into account. In addition, the model considered the temperature is the same for the entire room. This does not allow considering local discomfort due to the uneven temperature in the room and the temperature difference between the floor and the ceiling. Second, current state of the ANN cannot allowed predict temperature in time. At this moment, ANN only can output PMV value from concrete input parameters. The model does not take into account the number of sensors and their location in the room.

\section{Conclusions and future research}

The main goal of this work was to create a neuro-fuzzy model of indoor climate control and to present the general architecture of this model, which will be further developed by taking into account additional parameters that affect the microclimate in the room. The continued use of improved FLC based on other parameters (e.g. carbon dioxide concentration), as well as predicting indoor temperature based on environ-mental factors, is part of the future research plan.

Used in the model ANN achieved good accuracy in calculating the index of comfort PMV. The fuzzy controller operates not only with the temperature and humidity values, but also with the PMV index. This approach allows to improve the dynamic control of incoming air in order to provide a constant thermal comfort in the room. The combination of an artificial neural network (ANN) and a fuzzy logic controller (FLC) for regulating temperature and humidity in a room is a very interesting but not a new method. This article focuses on the optimal choice of parameters for a fuzzy controller, which is usually associated with the complexity of the formation and adjustment of the rules base.

Further development of this model assumes the take into account of short-term forecasting of changes in parameters and convective processes in the room.

The publication is made on the basis of materials of the international project «Modernization of the Curricula in sphere of smart building engineering - Green Building (GREB)» 574049-EPP-1-2016-1IT-EPPKA2-CBHE-JP and in the framework of the Erasmus+ program. This project has been funded with support from the European Commission. 


\section{References}

1. P.O. Fanger, Thermal comfort: analysis and applications in environmental engineering (McGraw-Hill. New York, 1972)

2. H. Huang, L. Chen, M. Mohammadzaheri, E. Hu, Procedia Engineering, 49, 142-151, (2012)

3. A.A. Argiriou, I. Bellas-Velidis, C.A. Balaras, Neural Networks, 13, 811-820, (2000)

4. P.M. Ferreira, A.E. Ruanoa, S. Silvaa, E.Z.E, Energy and Buildings, 55, 238-251, (2012)

5. F. Calvino, M. La Gennusa, G.Rizzo, G. Scaccianoce, Energy \& Buildings 36, 97-102, (2004)

6. A.I. Dounis, D.E. Manolakis, Appl Energy, 69, 119-144, (2001)

7. P. Berk, J. Rakun, P. Vindis, D. Stajnko, M. Lakota, DAAAM International Scientific Book, 117-128, (2010)

8. L. Zadeh, Fuzzy sets, fuzzy logic, and fuzzy systems: selected papers (River Edge, N.J.: World Scientific, Singapore, 1996)

9. K. D. Tarun, D. Yudhajit, AJER, 2, 86-97. (2013)

10. M. A. Al-Gunaid, M. V. Shcherbakov, D. A. Skorobogatchenko, A. G. Kravets, V. A. Kamaev, IISA, 7, 1-8. (2016)

11. A. V. Karpenko, I. YU. Petrova, IISA, 8, 1-6. (2017)

12. GOST R ISO 7730-2009, Ergonomics of the thermal environment. Analytical determination and interpretation of thermal comfort using calculation of the PMV and PPD indices and local thermal comfort criteria (2011) 38 p.(in russian)

13. Hygienic requirements to occupational microclimate (SanPiN 2.2.4.548-96, 1997, 8 p.),(in russian) 